\title{
Discursos ideológicos sobre a seca construídos na literatura e na música
}

\author{
Emanuel de Andrade Freire ${ }^{1}$
}

\section{Resumo:}

O cenário das consecutivas secas que atingiram o Nordeste brasileiro nos últimos cem anos sempre esteve presente nas narrativas literárias e poético-musicais, abrindo um debate através de seus discursos objetivos ou subjetivos, sobre o fenômeno natural que, na maioria das vezes, deixa marcas na geografia o semiárido nordestino, diante a escassez de chuvas, provocando impactos na rotina do sertanejo, como perda de lavouras, falta de água para consumo humano e animal. Atualmente, esse mesmo cenário se traduz numa outra realidade, de certa forma, distante das superadas frentes de emergência e da saga das migrações para os grandes centros. Este artigo faz uma análise da temática e do discurso ideológico utilizados por alguns autores no campo da literatura e da Música Popular Brasileira, ajudando a compreender, muitas vezes de forma lúdica, a visão de quem conhece de perto o problema em relação aos que produzem conteúdos estereotipados sobre o tema.

\section{Palavras-chave: Seca; Sertão; Literatura e Música Popular}

\section{Summary}

The scenery of dry consecutive that hit the Brazilian Northeast in the last one hundred years has always been present in the literary and poetic-musical narratives, opening up a debate through their objective or subjective speeches on the natural phenomenon that, for the most part, leaves marks in geography the semi-arid northeast, on the lack of rain, causing impacts on routine backcountry, such as loss of crops, lack of water for human and animal consumption. Currently, this same scenario translates into another reality, in a way, far exceeded the emergency fronts and the saga of migration to the big cities. This article analyzes the thematic and ideological discourse used by some authors in the field of literature and of Brazilian popular music, helping to understand, often playful way, the vision of those who closely know the problem than those who produce content stereotyped on the subject.

Keywords: Drought; Hinterland; Literature and Popular Music

\section{Resumen:}

El paisaje de sequías consecutivas que azotó el noreste de Brasil en los últimos cien años ha estado siempre presente en la narrativa literaria y poética-musical, la apertura de un debate a través de sus discursos objetivas o subjetivas, sobre el fenómeno natural

\footnotetext{
${ }^{1}$ Emanuel Andrade é jornalista, mestre em Ecologia Humana e Gestão Socioambiental, e professor do curso de Comunicação Social Jornalismo em Multimeios, da Universidade do Estado da Bahia (Uneb)
} 
que, en su mayor parte, las hojas marcas en la geografía del nordeste semiárido, por la falta de lluvia, causando impactos en la travesía de rutina, tales como la pérdida de las cosechas, la falta de agua para consumo humano y animal. Actualmente, este mismo escenario se traduce en otra realidad, en cierto modo, superó los frentes de emergencia y la saga de la migración a las grandes ciudades. En este artículo se analiza el discurso temático e ideológico utilizado por algunos autores en el campo de la literatura y de la música popular brasileña, ayudando a comprender, a menudo de manera lúdica, la visión de aquellos que conocen de cerca el problema de aquellos que producen contenidos estereotipado sobre el tema.

Palabras clave: Sequía; Hinterland; Literatura y Música Popular

\section{INTRODUÇÃO}

O universo árido da seca com seus cenários de escassez não está somente no plano real da rotina geográfica do Nordeste nem nas abordagens estereotipadas da grande mídia. Também se perpetua na literatura, na música e no cinema. Os impactos das médias ou longas estiagens e suas consequências na ecologia humana sempre estiveram presentes no noticiário jornalístico, sendo que, muitas vezes, os produtores de conteúdos informativos seja para televisão, rádio ou jornais impressos se utilizam dos impactos provocados pelas estiagens para desenhar de várias maneiras um cenário de destruição e atraso que acabam formatando ideias preconceituosas por parte do olhar das regiões Sudeste e Sul. Há veículos, contudo, que ampliam a cena como uma tragédia anunciada. Mapeando secas históricas do último século, podemos perceber que as abordagens se mantiveram estereotipadas, geralmente com imagens fotográficas repetitivas de chão calcinado, reservatórios vazios, panelas sem alimento e, na maioria das vezes, os ossos do gado espalhados pelo chão.

Há décadas o tema da seca se faz presente na realidade dos nordestinos tanto no sentido de proximidade geográfica como no discurso que aponta o fenômeno como a responsável pelo atraso econômico de uma das maiores regiões do país. É possível pontuar que a sua caracterização pelos diversos segmentos da sociedade se ancora no termo seca enquanto fenômeno climatológico a partir da falta de chuvas, do empobrecimento do solo ou da baixa do nível de água dos açudes, como por outro lado, mexe com a dimensão social, como reporta a imprensa, ao observar os desdobramentos provenientes dos períodos de estiagem. 
Além disso, o cenário das consecutivas secas que atingiram o nordeste brasileiro nos últimos cem anos sempre esteve presente nas narrativas literárias e poético-musicais, abrindo um debate através de seus discursos sobre o fenômeno natural que, na maioria das vezes, deixa marcas na geografia do semiárido nordestino, diante da escassez de chuvas. Este artigo faz uma análise da temática e do discurso ideológico sobre o semiárido presente na literatura e em composições musicais, que apresenta, de forma lúdica, a perspectiva de mundo e vivências de quem conhece de perto o problema em relação aos que produzem conteúdos estereotipados sobre o tema. Para tanto, neste artigo, discuto alguns dos aspectos presentes na construção literária e musical, buscando entrever questões que estão relacionados ao bioma caatinga e aos homens e mulheres que vivem nesse sertão e que produzem arte e cultura.

No plano da abordagem presente neste universo literário e musical, as cenas de retirantes e filas das emergências, criadas até início dos anos 80, ficaram no passado, mas nortearam muitas criações através da arte, como na música e literatura, conforme abordaremos neste artigo. Em certas situações provocaram uma espécie de catarse ancorada no discurso ideológico de seus autores. Contudo, composições recentes já circunscrevem outros espaços geográficos que também sofrem com a seca, o que pode assinalar uma outras perspectivas de enfrentar o problema social.

Antes de entramos nos argumentos expostos no horizonte da linguagem artística, podemos reforçar sob a ótica de vários pesquisadores sociais que a seca é apontada como fator determinante para a demarcação da região Nordeste. "O tema da seca foi, sem dúvida, o mais importante, por ter dado origem à própria ideia da existência de uma região à parte, chamada Nordeste, e cujo recorte se estabelecia pela área de ocorrência deste fenômeno" (ALBUQUERQUE JÚNIOR, 2011, p.120). Os primeiros relatos sobre esta problemática datam de 1552, três anos após a chegada do primeiro governadorgeral, Tomé de Souza, ao recém-descoberto Brasil (VILLA, 2000, p.17). Desde então, uma construção histórica realizada, em alguns casos, através da música, dos filmes, da mídia e da literatura fizeram com que o Nordeste, muitas vezes, fosse associado à ideia de seca - longe de formarem a imagem definitiva da região, porém, contribuindo para a construção do imaginário popular sobre este território.

Além disso, tal região acabou se transformando, principalmente após a estiagem de 1877-1879 (na qual aproximadamente 5\% da população brasileira morreram), em uma 
"região problema" (VILLA, 2000, p.83). Contudo, os diferentes cenários de cada seca também foram expostos nas telas de cinemas, nas telenovelas, na literatura, na poesia, na música popular. Muitas vezes, existe a presença de um discurso político que converge para apropriações dedisputas de poder, marcadamente de caráter eleitoreiro. Apesar das mudanças e avanços ocorridos, no âmbito das políticas públicas, atualmente, os diversos discursos midiático colocam o Nordeste na órbita das mazelas sociais.

Durval Muniz de Albuquerque Júnior (2011) observa que a crítica literária passa a explicar até mesmo o estilo dos autores nordestinos, a partir das imagens ligadas a este espaço:

Os autores são áridos, secos, pontiguados, lembram o deserto, o cacto. A identidade do autor é estabelecida com base na relação dele e de suas obras com o espaço que quer representar embora alguns, como Graciliano Ramos, procurem realmente afirmar no próprio estilo, na textura da linguagem, na sua forma de expressão, a imagem da região que constrói (ALBUQUERQUE, 2011, p.124).

A literatura abraçou um amplo papel como veículo de informação e debate ao trazer para a sociedade a problemática nordestina. Euclides da Cunha publicou Os Sertões em 1902, dividido em três partes: A terra, O homem e A luta, como estudo antropológico, sociológico, cientifico, poético e romanceado daquele povo místico conduzido pelo líder messiânico, Antônio Conselheiro, chefe dos homens do Sertão de Canudos, conforme definiu a mídia do Sudeste.

A Guerra de Canudos foi o que seria improvável território desconhecido para Euclides da Cunha, jornalista e escritor, tido como um dos intelectuais mais conceituados e respeitados do país no começo do século XIX. No auge da carreira, tinha 43 anos quando morreu, numa trágica história familiar. Obra clássica lançada em 1902, Os Sertões entra no ranking dos clássicos da literatura brasileira. O escritor, para muitos pesquisadores, aportou no Sertão da Bahia, caracterizado pelo bioma caatinga, sem talvez, conhecer com maior afinco sobre a fauna e a flora. Há historiadores que ainda hoje criticam a concepção e o olhar de discriminação que Euclides da Cunha desenhou em suas descrições ao falar da longa estiagem do ano em que se deu a guerra, tendo de um lado os seguidores de Antônio Conselheiro e do outro os homens da Guarda Nacional. 
Especialista em geografia cultural e professor da Universidade Federal de Pernambuco (UFPE), Caio Maciel, em texto publicado no livro- reportagem Os Sertões, assinado pela jornalista Fabiana Moraes (2010), traduz novas configurações para o Semiárido do ponto de vista estético e da convivência. Para ele, "as paisagens do Sertão seja do ponto de vista humano ou do quadro natural, possuem uma expressividade estética que tem magnetizado o olhar da sociedade brasileira desde muito tempo" (apud MORAES, 2010, p. 91).

Nesse contexto, o professor reflete sobre a retórica das secas e traz à luz do debate argumentos mais fortes na construção de soluções. Segundo Maciel, a retórica das secas é o exemplo mais banal de como se pode construir um discurso carregado de negatividade a partir dos elementos paisagísticos marcantes da região. Nesse sentido, o pesquisador questiona: "quem não reconhece facilmente o Nordeste seco através das imagens dramáticas de um açude esgotado ou da desolação de uma família de trabalhadores rurais diante da caatinga ressequida? (apud MORAES, 2010, p 91).

A despeito da veracidade contida nos espetáculos do fracasso social diante de um bioma semiárido que nem é das mais hostis do planeta, o imaginário sobre o sertão vem sofrendo uma reviravolta significativa nos últimos anos. Apoiando-se nessas visões trágicas e acrescentando-lhes ícones do atraso técnico e do tradicionalismo político - a desprezada lavoura de sequeiro, os coronéis travestidos de líderes democráticos e por ai vai, surgiu de uma antítese poderosa: o Sertão do agronegócio, da irrigação e das transposições das bacias hidrográficas (MACIEL apud MORAES, 2010, p.91).

São muitos os discursos reproduzidos que associam a região a tradição de uma ambiente de longa estiagem costurando aspectos informativo, crítico e até de denúncia. Uns ganham descrições coerentes e reais de quem, realmente, conhece de perto, como nativo, a realidade do que muitos chamam de fenômeno natural, enquanto outros deturpam de forma tendenciosa a realidade das estiagens, para compor uma imagem crítica em torno do povo da região, principalmente os que vivem nas áreas rurais.

Mergulhando um pouco na memória da temática na plataforma da literatura, é só dar um salto lá na segunda metade da década de 30, quando o alagoano Graciliano Ramos escreveu Vidas Secas que se traduz numa significação menos aparentemente, contudo central. Com sua narrativa forte, o romance foi construído a partir do núcleo do conflito representado pelo casal de retirantes Fabiano e Sinhá Vitória. Ele ajuda a conduzir a 
narrativa, como personagem que se ligou de forma visceral ao meio e sobrevive às secas por sua intimidade com a terra, com seu mundo na imensidão da caatinga.

Como bagagem, traz os comportamentos hereditários e uma certeza de ser vitorioso. Depois de sobreviver a mais uma seca quando se estabelece uma nova fazenda, ele enaltece sua resistência exclamando sozinho: "Fabiano você é um homem" (RAMOS, 1997, p. 18). Nessa frase, há toda uma satisfação de ser alguém que se sobrepõe às dificuldades de uma região impiedosa. O personagem passa logo do orgulho para uma fase de dúvida, vendo como um simples cabra "ocupado em guardar as coisas dos outros". E depois, em outro momento, murmura: Você é um bicho Fabiano, esbravejou.

Como bem conduziu Graciliano, seu personagem se orgulha de ser parte de uma paisagem que só admite os mais resistentes. Lá pelo meio do romance, percebe-se que os acontecimentos conduzem Fabiano a concluir que sem a linguagem não se é nada. A linguagem verbalizada tende a se tornar efetiva e se condiciona a dois fatores: à língua e à fala. Como bem observa Saussure (1966, p. 25) um signo é uma relação entre um significante (um som, uma imagem acústica ou um grafema) e um significado (um conceito). Assim, podemos compreender que são tantos os significados e conceitos que se entrecruzam no universo das interpretações.

Todavia a seca não é fator determinante na obra, como muitos pensam, mas é pano de fundo em várias passagens. A seca é tema frequente na literatura que aborda desde um simples fenômeno climático, estando na origem de todos os problemas do espaço onde ocorrem e até mesmo um problema que alavanca implicações econômicas, políticas e sociais, agravando uma estrutura socioeconômica de desigualdades sociais profundas. Em Vidas Secas, conforme pontua Albuquerque Júnior (2011), importam menos as consequências externas da seca do que o espírito dos personagens como manifestação do humano.

O espaço surge por meio dos olhos diferenciados de seus personagens. Um espaço fruto de diferentes visões que tecem uma rede de estranhezas; um espaço que se apodera dos personagens, porque está atravessado por um poder humano, por uma dominação que não estão perceptíveis a todo os olhares: os mistérios na natureza (ALBUQUERQUE JÚNIOR, 2011, p.265). 
Nascido em Quebrangulo, Graciliano era um intelectual de olhar aguçado para as mazelas da época. Chegou a ser prefeito, em 1928, de Palmeira dos Índios até rumar para o Sudeste com o objetivo de exercer a brilhante profissão de escritor, jamais como um retirante. Certa vez, o escritor José Lins do Rêgo aportou em Palmeira dos Índios, em busca do homem que mais sabia de mitologia no sertão. A pacata cidade era a segunda terra natal do Velho Graça, como era chamado pelos amigos, para onde sua família se mudara em 1910, depois de alguns anos na capital Maceió. Era o "homem sábio" que publicara seu primeiro conto $O$ pequeno pedinte, no jornal do internato onde estudava, era o mesmo que varava madrugadas com caneta e papel, cachaça, fumo e dicionário.

No texto A Descoberta da Linguagem, escrito para integrar o Dossiê Graciliano Ramos - No meio do caminho tinha um estilo de Pedra-, da Revista Entre Livros, o jornalista e crítico Miguel Sanches Neto (2006) acena que Vidas Secas tem sido lido como narrativa sobre retirantes e dramas sociais, mas se refere sobretudo a um romance que se refere à urgência da leitura e ou a descoberta da linguagem.

\section{O discurso poético-musical sobre o sertão}

O Rei do Baião, Luiz Gonzaga, o compositor Catulo da Paixão Cearense, o maranhense João do Vale e o poeta cearense Patativa do Assarétalvez sejam os autores das mais representativas canções com narrativas sobre a seca. Através das letras e músicas pungentes, ambos denunciaram, de forma poética, os nós que, historicamente, a seca provoca na rotina de populações atingidas, mas nenhum deles jamais deixou de lançar um olhar esperançoso sobre o problema.

Para falar de seca, dor e saudade na teia dos versos, é só mergulhar nos versos do clássico Asa Branca (1947), parceria de Luiz Gonzaga com Humberto Teixeira:

"Quando olhei a terra ardendo Com a fogueira de São João Eu perguntei a Deus do céu, ai Por que tamanha judiação Eu perguntei a Deus do céu, ai Por que tamanha judiação Que braseiro, que fornaia Nem um pé de prantação Por falta d'água perdi meu gado Morreu de sede meu alazão" 
No seu último show, Luiz Gonzaga declarou querer ser lembrado como sanfoneiro que amou e cantou muito seu povo, o sertão, as aves, os animais, os padres, os cangaceiros, os retirantes, os valentes, os covardes e o amor. Em quase todos os seus discos, o Rei do Baião traduziu de fato, as alegrias e as dores dos sertanejos, sempre desenhando o cenário real dos vários sertões em um só. Em Vozes da Seca (1963), uma toada-baião que trafega numa mistura de discurso político e manifesto, Luiz Gonzaga e Zé Dantas coletivizam os apelos, num grito de desilusão, pelo viés político, provocando as autoridades:

\footnotetext{
"Dê serviço a nosso povo, encha os rio de barrage. Dê cumida a preço bom, não esqueça a açudage. Livre assim nóis da ismola, que no fim dessa estiage. Lhe pagamointé os juru sem gastar nossa corage Se o doutô fizer assim salva o povo do sertão Quando um dia a chuva vim, que riqueza pra nação!"
}

Ao final, a esperança permeia a problemática, com o sonho de inverno e chuva. Caracteriza-se aí mais uma construção poética que denuncia o descaso e a omissão dos governantes no que se refere ao combate à seca. A toada Vozes da Seca continua atual e pode funcionar como um 'tapa de luva' na classe política brasileira. Os autores não deixam escapar a ideia de que a seca é um fenômeno climático que irriga em muitos casos interesses eleitoreiros e oportunismo.

Outra canção que se tornou referência e apelo no contexto da seca nordestina foi Súplica Cearense, do cantor, radialista, humorista e artista de circo baiano Waldeck Artur Macedo, mais conhecido como Gordurinha, em parceria com o compositor Nelinho, lançada em 1960 e gravada pelo próprio Gordurinha. A canção, conhecida pela gravação original em 1960, chegou a vender naquela época sem internet cerca de 400 mil cópias. A música foi composta em um programa de televisão que arrecadava dinheiro para ajudar a população do nordeste, desta vez, não por conta da seca, mas por uma enchente que destruíra centenas de casas.

Gordurinha e Nelinho, com seus talentos unidos, fizeram a música no camarim e apresentaram ao vivo. Posteriormente, foi regravada por Luiz Gonzaga, Jackson do Pandeiro, Elba Ramalho, Fagner e até, mais recentemente, em 2014, pelo grupo jovem 
Falamansa, em homenagem ao rei do baião. A letra seguem também em tom de apelo emocional:

"Oh! Deus, perdoe este pobre coitado

Que de joelhos rezou um bocado

Pedindo pra chuva cair sem parar

Oh! Deus, será que o senhor se zangou

E só por isso o sol arretirou

Fazendo cair toda a chuva que há

Senhor, eu pedi para o sol se esconder um tiquinho

Pedir pra chover, mas chover de mansinho

Pra ver se nascia uma planta no chão

Oh! Deus, se eu não rezei direito o Senhor me perdoe,

$\mathrm{Eu}$ acho que a culpa foi

Desse pobre que nem sabe fazer oração"

Meio século atrás, as letras eram feitas com realismo sem deixar de evocar o sentimentalismo do sertanejo. No final dos anos 60, o Brasil ganhou a forte, bela e politizada Carcará, de João do Vale, que pontua também, o cenário da seca/inverno, usando a ave de rapina da família dos falconídeos como personagem central pra imprimir também cenas agonizantes da estiagem.

"Carcará, lá no sertão.

É um bicho que avoa que nem avião.

É um pássaro malvado

Tem o bico volteado que nem gavião.

(...) O sertão não tem mais roça queimada

Carcará mesmo assim num passa fome

Os burrego que nasce na baixada

Carcará, pega, mata e come.

O mesmo João do Vale, no começo dos anos 80, compôs para um disco de Raimundo Fagner uma espécie de crônica-canção que a batizou de Orós 2, neste caso confronta os estragos da seca e da cheia no Nordeste:

"Não é só fala de seca

Não tem só seca no sertão

Quase acabava meu mundo

Quando o Orós impanzinô

Se rebentasse matava

Tudo que a gente plantô

Se não é seca é enchente

$\mathrm{Ai}$, ai, como somo sofredô

Eu só queria saber

O que foi que o Norte fez

Pra vivê nesse pená 
Todo nortista é devoto

Não se deita sem rezar

Se não é seca, é enchente, dotô

Que explicação me dá?”

No campo da música nordestina, há sempre expressões de uma realidade muitas vezes sofrida, mas costuradas em seus versos com irreverência e criatividade. Na escalada de grandes temas, no livro Luiz Gonzaga: A música como expressão do Nordeste, José Farias dos Santos(2004) sintetizou os temas-chaves da canção nordestina em quatro: crueldade da seca e migração; proteção divina; relação homem-natureza e desejo de retorno e contraste-rivalidade entre Nordeste e Sudeste.

A geração da chamada MPB surgida na transição de década de 60 para 70 e que bebeu na fonte do rei do baião, a exemplo de Fagner, Belchior, Zé Ramalho, Alceu Valença, Geraldo Azevedo e Djavan - todos nordestinos, mantiveram os discursos de seu ídolo, mas também deram nova roupagem em alguns clássicos e, ainda, carimbaram novo olhar direcionado aos problemas que se repetem no Nordeste. O compositor Djavan, no disco Malásia (1996) com sacadas jazzísticas e abordagens rurais (através da regravação de Correnteza, de Tom Jobim), traz também a bela e descritiva Seca. Na letra, o compositor questiona, perante Deus, o fenômeno e suas consequências:
"A terra se quebrando toda
A fome que humilha a todos
Vida se alimenta de dor
Que pobre povo sem socorro
Por que será que Deus pôs ali
O ser pra ser assim sofredor
Sob a brasa do sol padecer
$\mathrm{O}$ desdém do poder fingido
Sem saber o que é ser feliz
Viver, como se diz, dá medo
Apesar de se ter céu azul
O mesmo lá do sul, mesmo Deus"

No panorama do cancioneiro nacional, vale perguntar que papel as palavras desempenham numa canção. As respostas são inúmeras. Diante da temática da seca, é notório que, em cada composição, seus autores não escondem o sentimento de lamentação e a condição de pertencimento sobre a realidade de seu povo. A música atravessou a ponte do século XX para o XXI, mas a seca continua ganhando novas abordagens. 
Curiosamente, aas canções mais contemporâneas saem do foco apenas nordestino e se espalham por outras geografias. No novo Cd Carbono, Lenine (2015), em parceria com o compositor, letrista e jornalista Carlos Rennó, descreve em Quede a água? a seca que ultrapassa os limites do sertão nordestino e migra para outras regiões Sudeste:

\author{
“A seca avança em Minas, Rio, São Paulo \\ O Nordeste é aqui, agora \\ No tráfego parado onde me enjaulo \\ Vejo o tempo que evapora \\ Meu automóvel novo mal se move \\ Enquanto no duro barro \\ No chão rachado da represa onde não chove \\ Surgem carcaças de carro \\ Os rios voadores da Iléia \\ Mal desaguam por aqui \\ E seca pouco a pouco em cada veia \\ O Aquífero Guarani \\ Assim do São Francisco a San Francisco \\ Um quadro aterra a Terra \\ Por água, por um córrego, um chovisco \\ Nações entrarão em guerra \\ Quede água? Quede água? \\ Quede água? Quede água? \\ Agora o clima muda tão depressa \\ Que cada ação é tardia \\ Que dá paralisia na cabeça \\ Que é mais do que se previa \\ Algo que parecia tão distante \\ Periga, agora tá perto \\ Flora que verdejava radiante \\ Desata a virar deserto"
}

A canção é bem imagética, relacionando passado com o presente, mas no mesmo horizonte do fenômeno da estiagem, os compositores - um pernambucano (Lenine), outro paulista (Rennó) - unem as forças poéticas para exprimir os novos aspectos da seca que sai da caatinga e avança nas metrópoles brasileiras, como São Paulo, que tem enfrentado problema de abastecimento de água e longa estiagem com seca, que, contraditoriamente, é chamado pela mídia de crise hídrica. Quase no final da letra os autores chamam a sociedade para agir antes que seja tarde:
"Agora é encararmos o destino
E salvarmos o que resta
aprendermos com o nordestino
Que pra seca se adestra
E termos como guias os indígenas
E determos o desmate 
E não agirmos que nem alienígenas

No nosso próprio habitat"

O Brasil sempre respirou o Nordeste. Não por acaso o país começou a traçar sua história pela Bahia com o desembarque dos portugueses. O Nordeste sempre marcou presença em todos os aspectos principalmente na diversidade cultural. Já se escreveu em forma poética a idéia de tornar o Nordeste independente. Seja em letra ou música, com seca ou chuva, o Nordeste tem suas cores e seus encantos. Há discursos mais humanizados em favor de toda essa riquíssima região, mas por outro lado, há sempre vestígios de outros discursos polifônicos principalmente na agenda da imprensa e que associam a região apenas à seca e à falta de perspectiva, quando na verdade a realidade tem se configurado de outra forma com olhar mais positivo por parte do Nordeste e dos nordestinos.

\section{REFERÊNCIAS}

ALBUQUERQUE JÚNIOR, Durval Muniz de. A Invenção do Nordeste e Outras Artes. 5. Ed. São Paulo: Cortez, 2011.

KÜNSCH, Dimas Antônio. Maus pensamentos: os mistérios do mundo e a reportagem jornalística. São Paulo: Annablume, 2000

MORAES, Fabiana. Os Sertões - um livro reportagem. Recife: Ed, Cepe, 2010.

RAMOS, Graciliano. Vidas Secas. São Paulo: Record, 2002.

Falta o autor deste. Jornalismo X Literatura - Fronteira entre ficção e realidade. In: Revista Entre Livros: Ano 1,.nº 11, São Paulo: Ed. Duetto, 2005.

SANCHES NETO, Miguel. Dossiê letras Secas de Graciliano: no meio do caminho tinha um estilo de Pedra. In: Revista Entre Livros: Ano 2, nº19, São Paulo: 2006, Ed Duetto.

SANTOS, JOSE FARIAS. Luiz Gonzaga: A música como expressão do Nordeste. São Paulo: Ibrasa: 2004.

SAUSSURE, Ferdinand de - Cours de Linguistique Générale. Paris:Payot, 1966. P. 25

VILLA, Marco Antonio. Vida e morte no sertão: história das secas no Nordeste nos séculos XIX e XX. São Paulo: Ática, 2000.

\section{DISCOGRAFIA}

DJAVAN. Malásia[Cd]: Rio de Janeiro: Sony Music, 1998.

GONZAGA, Luiz; TEIXEIRA, Humberto. Asa Branca "Disco de Ouro"[Vinil]: Rio de Janeiro: RCA, 1975.

GONZAGA, Luiz; DANTAS, Zé. Luiz Gonzaga canta seus sucessos com Zé Dantas [Vinil]: Rio de Janeiro: RCA, 1970.

GORDURINHA. "Súplica Cearense", Gordurinha(reedição-[Vinil]: São Paulo: Phonodisc Mid: 1987.

LENINE; WINISK, José Miguel. Carbono[Cd]: Universal Music, 2015.

VALE, João do. Qualquer Coisa[Vinil]: Rio de Janeiro: CBS, 1982.

VALE, João do; CANDIDO, José. Nova História da Música Popular Brasileira[Vinil]: Rio de Janeiro: Editora Abril Cultural, 1977. 